\title{
La solidaridad relativa
}

\section{The relative solidarity}

Cipriani, Roberto (2009), El pUeblo solidario. Nahuatzen: DE LA CULTURA PURÉPECHA A LA MODERNIZACIÓN, El COlegio MeXiquense, ZinACANTEPEC, 339 PP., ISBN 978-607-776I-02-0. ${ }^{1}$

Hasta la segunda mitad del año 2009 no hubo más libro sobre Nahuatzen que el realizado por Lucía García López (1984): Nahuatzen, agricultura y comercio en una comunidad serrana. Éste es un libro cuyo volumen parece reflejar la escasa importancia que se le había prestado a la localidad en el campo de la investigación social. Casi podría decirse que no era de esperarse otra cosa porque inmediatamente a su noroeste, a cinco kilómetros en línea recta, se encuentra un monstruo tan apetecible, apetitoso y tan buen comensal que ha devorado buena parte de la atención de políticos e investigadores (Beals, 1992; Márquez, 1986; Calderón, 2004; Pedroza, 2009), tanto como ha atrapado a la modernidad misma para llevarla a las entrañas de su ser purépecha: Cherán.

Un buen día, obedeciendo a un plan trazado mucho tiempo atrás, llegó Roberto Cipriani a la Meseta Purépecha y Nahuatzen fue convertido en objeto de estudio como parte de un proyecto internacional de investigación profunda de tres comunidades en contextos diferentes (Orune, en Italia; Episkeri, en Grecia; y Nahuatzen, en México), pero inmersas es la aparente contradicción modernidad-tradición. El producto debía, entre otras cosas, llevar a la práctica un ejercicio multidisciplinario cuyo producto debía dar cuenta del efecto del proceso globalizador en comunidades periféricas y rurales en resistencia y/o adaptación de estilos de vida, sistema de valores y, claro, prácticas solidarias, entre otros aspectos socioculturales.

La investigación arrojó una serie de datos (históricos, económicos, políticos, religiosos y sociales) que conforman la unicidad de Nahuatzen como -nos dice Cipriani- pueblo mestizo, muy discutiblemente purépecha pero próximo a la cultura indígena de la etnorregión, tanto por su pasado como por los proyectos políticos de algunas de sus facciones, clicas u otros grupos sociopolíticos. Es evidente que la tesis de Luis Vázquez (1992) en torno de la purepechización de los tarascos se desliza sin pudor en el texto, lo que no constituye, a mi juicio, un desacierto.

\footnotetext{
${ }^{1}$ Esta obra contiene un croquis, un fragmento del Lienzo de Nahuatzen (dibujo), 24 cuadros estadísticos y referencia de 303 materiales bibliográficos, cuatro obras videográficas y tres cinematográficas referidas, entre ellas un filme de investigación del autor, también incluye un disco compacto.
} 
El autor es uno de esos investigadores iconoclastas, que no le rinde culto ciego a la teoría ni a los conocimientos previamente elaborados, pero no los desdeña. Al contrario, la liberalidad en la exposición y el análisis son patentes en su método de exposición: allí donde se encuentra con el dato lo vincula con algún planteamiento teórico y sigue adelante, como cuando vincula (capítulo III) al número 12 con la cosmovisión tarasca mediante la presencia de 12 huananchecha (doncellas que cargan en andas a la Inmaculada Concepción o cualquiera de sus advocaciones): al respecto habría que advertir al lector que el número no corresponde con los meses del año purépecha, puesto que la importancia de ese número vino en los arcones de los frailes adherido al calendario y, al parecer, a las estrellas que coronan a la Inmaculada Concepción (vid. la Inmaculada Concepción de Giovanni Battista Tiepolo, por ejemplo); esa misma confusión aparece en algunos pueblos purépechas que conservan el cargo del Temben Tsimani Miyuri (los que cuentan de doce en doce), y no porque el sistema numérico purépecha tuviera como base el 12, sino porque tenían la obligación de proporcionar 12 monedas de la más alta denominación al párroco. El 12 corresponde más al ciclo calendárico cristiano que al solar prehispánico tarasco. En ese mismo tenor, los purepechólogos puristas podrán asirse de la nota desafortunada en la que afirma que el churipu (caldo de res con chile, col y zanahoria) se cocina con korundiicha (piezas de masa de maíz que toman la forma de las manos superpuestas formando una cruz, en forma de estrella) y que la propia korunda ha sido ya sustituida por las ichuskuticha (tortillas); o a aquélla otra en la que afirma que San Juan es la cabecera municipal de San Juan Nuevo, cuando la localidad de San Juan Nuevo es la cabecera municipal de Nuevo Parangaricutiro (Topete, 2007). Habría que recordar a todo lector que no están allí las principales virtudes del libro.

La misma osadía manifiesta Cipriani con el manejo del devenir: desde el primer capítulo nos queda claro que el autor no le teme al tiempo. En efecto, con frecuencia liga datos de la preteridad con eventos presentes y procede a una interpretación que abandona inmediatamente para regresar al pasado sin el menor recato, pero también sin justificación de por medio. Quizá para algunos resulte chocante, pero dejaría de serlo si consideramos que el método de análisis y el de exposición parecen correr, en momentos, paralela e interactivamente.

El lector que sigue de la mano la exposición desde el principio se familiariza con las simpatías que el autor dispensa a las formas procesuales de Boudon y a la categoría de liminalidad de Turner reelaboradas por él; pero no crea con ellas una mascarilla para la organización y análisis de los datos. Al contrario, y dicho sea a guisa de ejemplo, hay un apunte de método de trabajo de campo digno de ser leído por el estudiante novel 
en relación con la forma de atajar el registro de las fiestas, aunque para seguir el hilo conductor sea necesario esperar casi 300 páginas y encontrarnos con la propuesta metodológica o metametodológica abierta, flexible, creativa, sin cartabones ni cuadriculaciones; que recurre a todas las técnicas posibles y a los procedimientos metodológicos al alcance.

Cipriani no escatima osadía ni erudición y, tomado de la mano de ambas, se declara partidario de Eduardo Ruiz, Nicolás León y Eduardo Corona en torno a la tesis de los vínculos culturales entre purépechas con las culturas peruanas (Sánchez, 1999), en tiempos en que la polémica aún no tiene una salida clara. Además, es también un apasionado del dato y para consolidarlo puede ir a fuentes tan diversas como el Lienzo de Nahuatzen, una rima, o al omphalus representado por una fuente de la localidad, desafiando a teóricos de la talla de Mircea Eliade (1985) y Jan Hani (1983), quienes sostienen que esa significación le corresponde al templo o al símbolo cultural del axis mundi.

En el segundo capítulo despliega su pasión por los soportes empíricos, y con la perspectiva diacrónica de los procesos sociales emprende un ejercicio sociológico e histórico centrado en el Nahuatzen colonial y de los siglos XIX y xx. Por demás está decir que el apartado está bien documentado, aunque los académicos e investigadores lamentarán que la mayor parte de las fuentes utilizadas son secundarias.

Un capítulo adelante Cipriani deja a descubierto la influencia que en su obra ejercieron Eduardo Corona Núnez y Eduardo Ruiz (1971), a quien Nicolás León criticó acremente en sucesivas ocasiones, pues consideraba que los relatos recuperados -por Ruiz- habían brotado de la imaginación de sus informantes. Con todo, Cipriani se adhiere a quienes sostienen el origen tawantinsuyano de los purépechas.

En la búsqueda de soportes empíricos con los cuales fortalecer su tesis de la solidaridad, recupera dos etnocategorías de considerable envergadura para conocer la cultura purépecha: jatsipeni (servir a los demás) y marhuatspeni (servir a la sociedad), según sus informantes. Y si de ofrecer servicio -como elemento del cargo- se trata, el lector debe estar avisado que la primera etnocategoría refiere no a cualquier servicio, sino al propio de un cargo o de representación de los humanos frente a los dioses y gobiernos, $\mathrm{y}$ al carguero se le selecciona por elección divina o por la propia dignidad investida en el seleccionado: refiere al estar en el cargo; en cambio, el segundo refiere al servicio como tal: marhuatspeni indica servir a la gente y a los dioses (manar atspeni).

Quizá la pérdida notable del purépecha haya arrastrado consigo otras claves de la solidaridad que se expresan como ofrecimientos, donaciones (parantiecha) indicadas en la pintekwa (El Costumbre, es decir, el conjunto de normas y valores que indican cómo vivir, cómo hacer, cómo decir, 
cómo pensar) a la que el autor, extrañamente, no recurrió a pesar de su búsqueda de lo que llama, siguiendo a Farris, ideas clave (core ideas).

También es de lamentar que hayan quedado fuera de la etnografía y del análisis las etnocategorías que Mario Padilla (2000) considera fundamentales para entender el sentido de los cargos: janganganperata (reconocimiento, reconocerse mutuamente a la cara) y kashumbikwa (conducta reverencial, urbanidad, etiqueta). La primera, porque el espacio de la fiesta de barrio y la local tiene, entre otros sentidos ése: propiciar el reconocimiento de los propios parientes, de los propios vecinos, de los propios del pueblo, según sea el caso; el segundo, porque establece las formas de respeto, de vivir jerarquías, roles, estatus y de convivencia cotidiana. Asimismo, más de algún purepechólogo observará que las consideraciones otorgadas a la Danza de los Viejitos (Taré Tsimani), en tanto tradición reciente, devienen excesivas, cuando no desacertadas; sin embargo, habrá que recordar que en materia de tradiciones la creación, la invención de las mismas es una constante en todos los pueblos del mundo, y ello no las expulsa de su cultura, ni les resta sentido, significación.

El capítulo iv es un ejercicio formidable de historia agraria que llevó a Nahuatzen no a la propiedad comunal -a diferencia de otras localidades, como Charapan, Ocumicho, Cocucho y Tanaco-, sino a la pequeña propiedad, al terratenientismo y al minifundismo en contraparte. Sin ese sustento parecería difícil hablar de una vida comunitaria, pero existe: la religiosidad popular es uno de los agentes facilitadores. Los lectores asistimos a contemplar a un Nahuatzen que aún intenta obtener la resolución presidencial para recuperar sus tierras en propiedad comunal, mientras que reconoce que no todas podrán regresar a dicho estatuto: dura realidad la de la propiedad comunal privatizada con una estructura comunal sin referencia territorial.

Poseedores principalmente de bosque, nos dice en el capítulo v, los nahuatzenses tienen el problema de la cercanía de Capacuaro, cuya fama de talamontes ilegales y depredadores es muy conocida en la Meseta Purépecha; Uruapan, que es un centro político y comercial de segundo orden; de Cherán, que había centralizado las políticas culturales diseñadas para la etnorregión y de una idea de propiedad privada importada que, en cierta medida - y aunada a las facciones en pugna- fue la causante del fracaso del astillero comunal, en lo que parece una copia de la debacle sufrida por Santa Cruz Tanaco (Topete, 2007). Además, el autor desvela ante nuestros ojos los problemas que por linderos y pretendida detentación ancestral, dos localidades, verbigracia Cherán y Nahuatzen, viven en la cotidianeidad, a la vez que desenmascara parte del rostro del cardenismo agrario, que proporcionó tierras a algunos que no las tenían, quitó a otros y dio más a algunos ya poseedores. 
Pueblo silvícola, agrícola, textilero, Nahuatzen no rebasa el mercado local y regional para la distribución y venta de sus productos, excepto los propietarios privados de los medios de producción que se han insertado en el mercado capitalista nacional e internacional. Y en ese mismo quinto capítulo, el lector no puede menos que sorprenderse al ver cómo un investigador empata cosmovisión con estadística referida a una cosecha obtenida para demostrar que el campesino nahuatzense es semitradicional, lo que no es poca cosa en términos de la concepción global que de la localidad genera el autor. El mercado de Nahuatzen desvela sus vínculos con Cherán y Paracho, cuya proximidad crea un corredor de distribución de productos cuyos extremos -agrego yo, no el autor- son Uruapan y Zamora. Las notas para un estudio regional parecen acumularse, pero no se desbordan de manera que se produzca un abandono de la localidad en estudio.

El capítulo sexto está fuertemente vinculado con el contenido del disco compacto incluido en la compra del libro. Aquí aparece nuevamente Turner, con sus conceptos de communitas y liminalidad para atraparlas y darles sentido en la fiesta, como momento antiestructural sujeto entre el antes y el después de la fiesta misma. En efecto, el autor destaca la importancia de la religión en términos de la identidad, lo que no es poca cosa: es casi imposible entender a los purépechas si no se toma en cuenta su religiosidad o catolicismo popular (Folk religión) como planteara Pedro Carrasco hace más de medio siglo.

El autor propone que el sistema de cargos, el artífice de la fiesta patronal (San Luis Rey), además de organizar la fiesta y proporcionar los momentos de comunión (el término es mío), ha creado problemas entre la Iglesia y la religiosidad popular. Cuestión de matices, habría que agregar: convivieron durante mucho tiempo hasta que el clero quiso tomar enteramente las riendas de las expresiones religiosas de los pueblos; esto hasta el Sínodo de Nueva Evangelización, que fue como una tregua a la pugna generada por la misma Iglesia, independientemente de que estemos o no de acuerdo con los sistemas de cargos.

Hacia el final, Cipriani aborda la actividad política hacia lo local y lo nacional por medio de los partidos políticos, apoyándose en estadísticas del Instituto Federal Electoral (IFE), para desvelar las alternancias que los partidos Revolucionario Institucional (PRI) y de la Revolución Democrática (PRD) han tenido en los ámbitos estatal y municipal luego de la aparición del Partido del Frente Cardenista de Reconstrucción Nacional (a propósito, la gente le llama El del Gallito) (Topete, 2007), y desvela que el interés más inmediato, es de esperarse, es el municipio y luego el estado. De allí en parte el triunfo del Partido Acción Nacional (PAN) en el año 2000. Pero hay algo más: Cipriani coloca en el análisis los proyec- 
tos políticos y económicos de orden individual, así como la reclusión intracomunal como única forma de contener los embates de la sociedad mayor que contiene a Nahuatzen. Uno podría esperar que el procesualismo apareciera en el corazón de este capítulo, pero no ocurre así porque el autor confía más en el dato que en la teoría, lo que es elogiable.

Nahuatzen es un pueblo solidario, reza el título. Lo es, pero no es solidario absoluta, ininterrumpida, incondicionalmente. Lo es en tanto hay un proyecto anticentralista, antinacional frente de sí, como lo fue antiespañol, anticriollo. No lo es per se, ni para siempre, ni de cualquier modo, sino que se entiende a partir de intereses, cálculos de oportunidades, reconocimientos. Aparece en la fiesta, cuando se ve amenazada, sobre todo por los movimientos políticos y económicos de la periferia. La fiesta es un espacio de contención, pero también un escaparate de conflictos, de cambios, de permanencias y de atenuación de conflictos intracomunitarios. La fiesta, por su parte, es liminalidad. Pero también tiene sus especificidades: espacio para el prestigio, para la comunión, para el religamiento, para la solidaridad. No es extraño el extraordinario énfasis puesto en ella porque convoca a casi todo el pueblo y porque antepone a la solidaridad el plano social antes que el político, lo clientelar, partidista, patronalista. Y el espacio de la fiesta es quizá uno de los mejores escaparates para poder ver los procesos autonómicos de que son capaces los purépechas de Nahuatzen.

Y podemos no estar de acuerdo con algunas de las interpretaciones que el autor propone en sus conclusiones, pero de que son novedosas, lo son, como la de que el castillo es un contraaltar del altar controlado por la institución eclesiástica..., o aquella otra en que rompe con la tradicional división de West (1948) para la etnorregión purépecha (La Sierra, La cañada, la zona lacustre y la ciénega), para colocar la que sus informantes le proporcionaron. O quizá haya quien le refute que la noción de solidaridad, tan amplia, flexible, que propone el autor, produce un velo de opacidad sobre elementos estructurales, como las relaciones de reciprocidad, de concentración-redistribución, de ayuda mutua, de generosidad, de cooperación o distribución del poder, pero lo que permanecerá en pie es la profusión de datos convocados y las perspectivas disciplinares con que se pudo ver a Nahuatzen que son, sin duda, la mejor aportación de Roberto Cipriani. 


\section{Bibliografía}

Beals, Ralph Larson (1992), Cherán: un pueblo de la sierra tarasca, El Colegio de Michoacán, Zamora.

Calderón-Mólgora, Marco Antonio (2004), Historias, procesos políticos y cardenismos. Cherán y la Sierra Purhépecha, El Colegio de Michoacán, Zamora.

Eliade, Mircea (1985), Lo sagrado y lo profano, Labor, Barcelona.

García-López, Lucía (1984), Nahuatzen, agricultura y comercio en una comunidad serrana, El Colegio de Michoacán, Zamora.

Hani, Jean (1983), El simbolismo del templo cristiano, José J. de Olañeta, Palma de Mallorca.

Márquez-Joaquín, Pedro (1986), "El casamiento en Cherán Atzícurin”, Relaciones, vir (28), El Colegio de Michoacán, Zamora, pp. 111125.

Padilla-Pineda, Mario (2000), "Sistema de cargos, intercambio ceremonial y prestigio", Cuicuilco, viI (19), Instituto Nacional de Antropología e Historia, México, pp. 117-134.

Pedroza, Jesús Ángel (2009), K'eri uantakua: minhuarhikua ka uantakua cherán anapu = territorio y lenguaje en la tradición oral de Cherán, Consejo Nacional para la Cultura y las Artes-DGCPI, Morelia.

Ruiz, Eduardo (1971), Michoacán: paisajes, tradiciones y leyendas, Balsal Editores, México.

Ruiz, Eduardo (2009), "Prólogo", <http://dieumsnh.qfb.umich.mx/ prologo_mich1.htm>, última modificación 28 de mayo.

Sánchez-Díaz, Gerardo (1999), "En torno a una discusión centenaria: el origen sudamericano de los tarascos" en Gerardo Sánchez Díaz y R. León Alanís (coords.), Historiografía michoacana, acercamientos y balances, Universidad Michoacana de San Nicolás de Hidalgo, Morelia, pp. 33-48. 
Topete-Lara, Hilario (2007), P'intekwa: la forma de hacer, vivir y ser en San Juan Nuevo Parangaricutiro, Michoacán, tesis doctoral, Escuela Nacional de Antropología e Historia, México.

Vázquez-León, Luis (1992), Ser indio otra vez. La purepechización de los tarascos serranos, Consejo Nacional para la Cultura y las Artes, México.

West, Robert C. (1948), Cultural Geography of the Modern Tarascan Area, Smithsonian Institution, Washington.

Hilario Topete-Lara Escuela Nacional de Antropología e Historia Correo-e: topetelarah@yahoo.com

Recibida: 23 de junio de 2010. Aceptada: 28 de junio de 2010.

Hilario Topete-Lara. Es licenciado en antropología social; maestro en historia/etnohistoria y doctor en antropología por la División de Estudios Superiores de la Escuela Nacional de Antropología e Historia (ENAH) del Instituto Nacional de Antropología e Historia (México). Es profesor de investigación científica y docencia, titular "C", en la ENAH. Cuenta en su haber con medio centenar de publicaciones entre libros (de autoría personal, editados, coordinados), artículos, ensayos, dossier, prólogos, presentaciones, reseñas y traducciones; además, ha producido paquetes didácticos y ha realizado guiones para exposiciones y video, entre otras actividades de extensión académica. Ha participado en eventos académicos y científicos nacionales e internacionales y ha presentado en ellos más de un centenar de documentos entre ponencias y conferencias; asimismo, posee el reconocimiento Promep hasta la fecha. Actualmente es responsable del proyecto de investigación formativa Los gobiernos locales y la organización social comunitaria, y el proyecto Eje Tlaxiaco. 